\title{
Novel optical PVC probes for on-site detection/determination of fluoroquinolones in a solid/liquid interface: Application to the determination of Norfloxacin in aquaculture water
}

\author{
Tâmara I.B. Silva, Felismina T.C. Moreira, Liliana A.A.N.A. Truta, M. Goreti F. Sales
}

\begin{abstract}

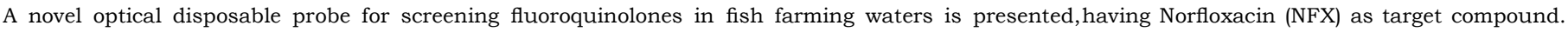

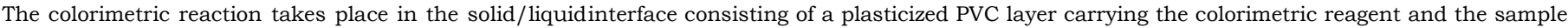
solution.NFX solutions dropped on top of this solid-sensory surface provided a colour change from light yellowto dark orange.

Several metals were tested as colorimetric reagents and Fe(III) was selected. The main parameters affecting the obtained colour were assessed

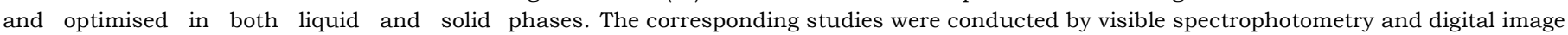

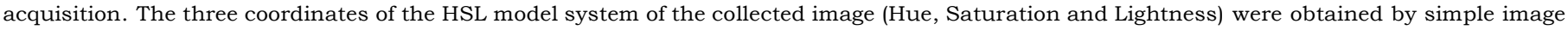
management (enabled in any computer).

The analytical response of the optimised solid-state optical probe against concentration was tested for several mathematical transformations of the

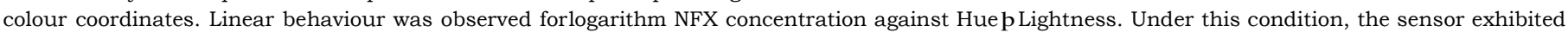

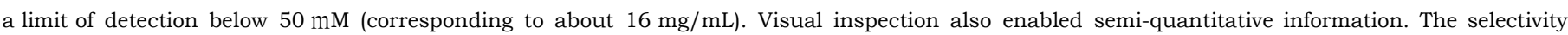
was ensured against drugs from other chemical groups thanfluoroquinolones.

Finally, similar procedure was used to prepare an array of sensors for NFX, consisting on different metal species. Cu(II), Mn(II) and aluminon were selected for this purpose. The sensor array was used todetect NFX in aquaculture water, without any prior sample manipulation.
\end{abstract}

Keywords

Solid-state optical probe, Aquaculture, Antimicrobial, Fluoroquinolones, Norfloxacin, Water

\section{Introduction}

Aquaculture is an important sector worldwide, granting fish meat to future generations at relatively low costs. Its great success comes however with many chemicals disposed throughout the environment, with great danger to finite water resources. This includes antibiotics, fungicidal, pesticides, hormones, anaesthetics, various pigments, minerals and vitamins.

Antibiotics are drugs with the ability to kill or inhibit the growth of microorganisms. Their use in meat producing animals has been controversial. The benefits of their use are obvious, but their abusing use leads to the accumulation of residues in different environmental sections and an increased risk for growth and promotion of bacterial resistance (Pico' and Andreu,
2007;Beausse, 2004; Karthikeyan and Meyer, 2006). Furthermore, their wastes are potentially persistent and can be found in fish and water (Beausse, 2004; Karthikeyan and Meyer, 2006; DíazCruz et al., 2003). The first measure to avoid this scenario is to prevent drug spread by having a strict control of the applied doses. This can be established by monitoring the waters from the tanks where the fish are being farmed. This should be done regularly and with a low cost/quick procedure. The drug concentration changes from the time of administration and additional costs in the fish production must be kept to a minimum.

Fluoroquinolones are one of such groups of antibiotics used in fish farming, already correlated to the emergence of resistant bacteria (Hoope, 2001). Many techniques have been employed for their determination in farmed fish and waters. These include the classical microbiological methods (Cabello, 2004; Park et al., 2007) that have the disadvantage of taking too long to produce an analytical result and being subject to biological variability. Separative methods based in liquid-chromatographic techniques coupled to mass-spectrometry (Kassab et al., 2005; Dufresne et al., 2007), 
fluorescence (Zhang et al., 2007; Chui-Shiang et al., 2008) and/or a combination of these (Schneider et al., 2005), and electrophoresis (McCourt et al., 2003) have also been used. These are great in terms of accuracy and robustness, but unable to carry out on-site analysis. Surface Plasmon Resonance and fluorimetric sensors have also been descried (Hueta et al., 1989; Jeon et al., 2008), but they use highly expensive and/or not-portable equipment.

An alternative procedure for field evaluations is a coloured sensing strip, made with low cost materials and allowing easy performance and quick response for a specific target analyte (Guerreiro and Sales, 2011). This is a kind of an optical sensor, where an immobilized reagent must be accessible to interact with the analyte (Wolfbeis, 2008). There are several strategies for reagent immobilization (Khezri et al., 2008; Jeronimo et al., 2007; Narayanaswamy, 2006), with polymeric entrapment by plasticized PVC allowing an easy cast procedure with relatively inexpensive material.

The reagent to immobilize must form a coloured complex with the target analyte. Many colouring agents exist in the literature for fluoroquinolones, including NFX (Kaur et al., 2008; Issopoulos, 1898). These include iron chloride(III), aluminon, cupper sulfate(II) and manganese chloride(II). To produce a useful optical probe, the colouring agent should also have a relative hydrophilic character. It must diffuse from the solid matrix towards the aqueous phase deposited on top of the sensory surface in order to meet the analyte and react with it. Metal species are always a good choice under these circumstances.

Thus, a novel colour disposable probe is presented for on-site detection of NFX. A selected metal is selected among several colouring agents and immobilized on a PVC membrane containing a plasticizer. It is deposited later over a polycarbonate solid support. NFX contacts with the immobilized metal and grants the formation of a coloured product detected by human eye. The same principle was applied to additional colouring agents, allowing multiple responses for the same target analyte.

\section{Experimental}

\subsection{Apparatus and reagents}

Spectrophotometric measurements were made in a Thermo $\mathbf{s}^{\mathbf{s}}$ Scientific, Evolution 300, spectrophotometer, carrying a $1 \mathrm{~cm}$ glass cell. The digital image of the solid surfaces was acquired by a digital camera Nikon. The Paint program of Windows was used for gaining the coordinates Hue, Saturation and Lightness of the HSL space. This specific colour model was used because it is available in any computer program of windows.

The $\mathrm{pH}$ of buffer solutions was measured in a pH Meter GLP 22, Crison $^{\mathbf{s}}$, connected to a combined electrode Consort. An ultrasonic bath, Fungilab SA, and/or a magnetic stirrer, Agimatic-N, were used to promote the dissolution of the solids. Commercial polycarbonate plates (Kartell) with $200 \mathrm{~mL}$ wells were used to cast the PVC-based probe.

All chemicals were pro-analysis grade and the ionised-water was employed (conductivityo $0.1 \mathrm{mS} / \mathrm{cm}$ ). NFX, bis(ethylhexyl)sebacate (BES), $O$-nitrophenyl octyl ether (oNPOE), di- $n$-octyl phthalate (DOP), dibutyl phthalate (DBP), bis(ethylhexyl)phthalate (BEP), phenyl glycil ether (PGE), poly(vinyl chloride) (PVC) of high molecular weight and manganese chloride were purchased from Fluka. Tetrahydrofuran (THF) was obtained from Panreac. Iron(III) chloride hexahydrate, aluminon and copper(II) chloride were purchased to Merck. Aluminum nitrate, lead(II) nitrate, ammonium molybdate tetrahydrate, nickel nitrate hexahydrate, cobalt(II) nitrate hexahydrate, tin(IV) chloride, vanadium(V), tetracycline, sulfadiazine, chlorpromazine, enrofloxacine, trimethoprim and oxytetracycline were produced by Sigma.

\subsection{Metal selection}

The colorimetric reaction was tested between NFX and Fe(III), Al(III), $\mathrm{Pb}(\mathrm{II})$, Aluminon, Mo(II), Mn(II), Ni(II), Cu(II), Co(II), Sn(IV) e $\mathrm{V}(\mathrm{V})$. Acidic and near neutral conditions were tested by preparing all solutions in $0.05 \mathrm{M} \mathrm{H}_{2} \mathrm{SO}_{4}$ and/or $1.0 \times 10^{-2} \mathrm{M}$ HEPES buffer.

The complexes were investigated by recording the visible spectra of individual and mixed components. Single or mixed solutions of $6.7 \times 10^{-4} \mathrm{M} \mathrm{NFX}$ and $3.3 \times 10^{-3} \mathrm{M}$ metal species were used for this purpose.

\subsection{Characterization/optimization of the coloured complex}

\subsection{1. $p H$ effect}

The effect of $\mathrm{pH}$ on the formation of metal/NFX complex was tested for $1.0 \times 10^{-3} \mathrm{M}$ acetate buffer with variable pHs: 2.4; 3.3; $4.1 ; 5.0$ or 6.1 . Metal standard solutions ranged from $1.1 \times 10^{-5}$ to $2.1 \times 10^{-4} \mathrm{M}$ with a NFX concentration set to $1.0 \times 10^{-4} \mathrm{M}$. Absorbance was examined at the wavelength of maximum absorbance $\left(1_{\max }\right)$ and plotted against concentration.

\subsubsection{Molar ratio}

Several solutions were prepared with varying amounts of metal (from $2.5 \times 10^{-5}$ to $2.5 \times 10^{-4} \mathrm{M}$ ) and a fixed NFX concentration $\left(1.02 \times 10^{-4} \mathrm{M}\right)$ in $\mathrm{pH} 3$ acetate buffer. The absorbance readings for $l_{\max }$ were plotted against metal concentration.

\subsubsection{Stability within time}

The absorbance of several solutions was monitored over $24 \mathrm{~h}$. The concentration of NFX was always $1.03 \times 10^{-4} \mathrm{M}$, prepared in acetate buffer $1 \times 10^{-3} \mathrm{M}, \mathrm{pH} 3$. Metal concentrations ranged from $3.33 \times 10^{-5}$ to $6.67 \times 10^{-4} \mathrm{M}$.

\subsubsection{Selection of metal concentration}

NFX solutions ranging from $2 \times 10^{-5}$ to $7 \times 10^{-4} \mathrm{M}$ and were prepared in $\mathrm{pH} 3.0$ buffer and fixed metal concentrations $\left(1.2 \times 10^{-2}, 1.3 \times 10^{-3}\right.$ or $\left.3.8 \times 10^{-4} \mathrm{M}\right)$. The absorbance values in $1_{\max }$ were plotted against NFX concentration.

\subsubsection{Effect of interfering species}

The interfering analysis was conducted for $3.50 \times 10^{-5} \mathrm{M}$ NFX

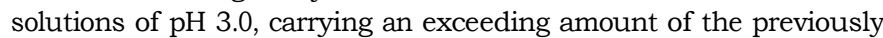
selected ligand $\left(1.0 \times 10^{-3} \mathrm{M}\right)$ and an additional divalent metal. $\mathrm{Ba}(\mathrm{II}), \mathrm{Pb}(\mathrm{II}), \mathrm{Hg}(\mathrm{II}), \mathrm{Mn}$ (II), $\mathrm{Cu}(\mathrm{II}), \mathrm{Zn}$ (II), $\mathrm{Cd}$ (II) and $\mathrm{Fe}(\mathrm{II})$ used.

Absorbance was read at $1_{\max }$ of the coloured complex. The degree of interference of each species was the relative error produced in the absorbance signal.

\subsection{Solid-state probe}

\subsubsection{Preparation}

Sensory surfaces were prepared by mixing specific amounts of metal, PVC and plasticizer. The mixture was stirred until the PVC was well moistened, and dispersed in $2 \mathrm{~mL}$ of THF. A volume of $50 \mathrm{~mL}$ was casted on each cavity of a polycarbonate plate and let dry for $30 \mathrm{~min}$.

Variable amounts of the selected metal $(0.50,1.00,1.50$ or $0.25 \mathrm{~g}$ ) were tested with $0.050 \mathrm{~g}$ of PVC, and $0.100 \mathrm{~g}$ of plasticizer. Different plasticizers were also employed using only the previously selected amount of metal: BES, oNPOE, DOP, DBP, BEP and PGE. Following, different amounts of plasticizer were tested for the previously chosen plasticizer: $0.02,0.030,0.05,0.10$ and $0.15 \mathrm{~g}$. Each condition was tested in at least two independent probes. 


\subsubsection{Analytical procedure}

NFX standard or sample $(150 \mathrm{~mL}$ of solutions ranging from $5.0 \times 10^{-5}$ to $1.0 \times 10^{-2} \mathrm{M}$ ) was added to each probe on the polycarbonate plate. A blank with buffer solution was used as control. The obtained colour was measured by taking a picture with a digital camera against a white background and treating the results with the Paint program of Windows. The HSL model was selected for this purpose, using Hue, Saturation and Lightness as coordinates. These values were manipulated to reach a linear or second degree function against NFX concentration. All measurements corresponded to the average of, at least, three assays with two probes.

\subsection{Cross-response to other antibiotics}

The response of the sensor was tested against other antibiotics used in aquaculture activities: tetracycline, sulfadiazine, chlorpromazine, enrofloxacin, trimethoprim and oxytetracycline. An aliquot of $150 \mathrm{~mL}$ of $1 \times 10^{-3} \mathrm{M}$ antibiotic solution was casted over the solid-state probe and the colour (kind/intensity) compared to the corresponding NFX standard.

\subsection{Array preparation}

The optimized composition of the colour-probe was applied to three additional metals. Overall, the array consisted on Fe(III), aluminon, $\mathrm{Cu}(\mathrm{II})$ and $\mathrm{Mn}$ (II) colouring agents deposited in different wells of the polycarbonate plate. It was calibrated for NFX concentrations ranging from $5 \times 10^{-5}$ to $1 \times 10^{-2} \mathrm{M}$.

\subsection{Application to water analysis}

The array of probes was applied to the analysis of water. Each probe was covered with $150 \mathrm{~mL}$ of sample or standard solutions without any prior preparation. Each calibration was carried out simultaneously with the sample analysis and required four probes: three standard solutions and one blank. The NFX concentration in each sample was determined by using the calibration curve data (slope and O.O.) for each metaltested.

\section{Results and discussion}

\subsection{Coloured complex}

The coloured complex may be formed when a fluoroquinolone such as NFX meets a suitable complexing agent that is inside the solid-state probe. This means that either NFX diffuses inside the polymeric matrix of the probe or the complexing agent diffuses outside to the sample aqueous phase. The former possibility is hindered by NFX size but the later may be favoured by choosing a complexing agent with a strong hydrophilic character.

\subsubsection{Ligand}

In general, several metals were tested as possible complexing agents for NFX: $\mathrm{Fe}(\mathrm{III}), \mathrm{Al}(\mathrm{III}), \mathrm{Pb}(\mathrm{II})$, Aluminon, Mo(II), Mn(II), $\mathrm{Ni}(\mathrm{II}), \mathrm{Cu}(\mathrm{II}), \mathrm{Co}(\mathrm{II}), \mathrm{Sn}(\mathrm{IV})$ and $\mathrm{V}(\mathrm{V})$. Each species was tested in acidic and near-neutral conditions because the kind/intensity of a coloured product varies with the $\mathrm{pH}$. Alkaline conditions were not evaluated because, in general, metals form highly insoluble compounds with hydroxides.

The main results are listed in Table 1. Only Fe(III), Aluminon, $\mathrm{Mn}(\mathrm{II})$ and $\mathrm{Cu}$ (II) ligands showed colour changes that may fit a screening application of NFX on a solid-state probe. Fe(III) gave the strongest colour intensity change, in both $\mathrm{pH}$ conditions tested, and was therefore selected for furtherstudies.

\section{2. $p H$ effect}

The form and degree of protonation of iron species is strongly dependent on the $\mathrm{pH}$. Iron becomes insoluble from $\mathrm{Fe}(\mathrm{OH})_{3}$ species, occurring for $\mathrm{pH} 42.5$. In $\mathrm{pH} 6$, the insolubility of iron is almost complete, remaining in solution a very small fraction of $\mathrm{Fe}(\mathrm{OH})_{2}^{\mathrm{b}}$ and $\mathrm{Fe}^{3} \mathrm{~b}$. Accordingly, a $\mathrm{pH}$ transition from 6 to 2 increases the fraction of soluble iron, accounting for the formation of novel iron species, such as $\mathrm{Fe}(\mathrm{OH})^{2 \mathbf{b}}$ and $\mathrm{Fe}_{2}(\mathrm{OH})_{2}^{4} \mathbf{b}$ (Marti et al., 2000).

In general, the absorbance increased for increasing concentrations of iron (ensuring of course exceeding and constant amounts of

NFX) in all pH ranges. This was exactly as expected because

increasing amounts of $\mathrm{Fe}(\mathrm{III})$ allowed the formation of a greater amount of complex, which in turn resulted in increased absorbance.

The exact behaviour was different in each $\mathrm{pH}$ condition. The colour of the blank solution (without NFX) changed in a different way than that of the complex (Fig. S1), and a linear trend was only observed for $\mathrm{pH}$. The linear pattern was found from $1.1 \times 10^{-5}$ and $1.7 \times 10^{-4} \mathrm{M}$ with a molar extinction (e) of $812.2 \mathrm{~L} / \mathrm{molx} \mathrm{cm} . \mathrm{pH} 3$ was therefore selected for further trials.

\subsubsection{Molar ratio}

Several solutions containing a fixed amount of NFX and variable concentration of Fe(III) ( 710 times NFX molar concentration) were tested. The absorbance of each complex solution was subtracted from that of solutions prepared without NFX.

Table 1

Preliminary tests of NFX with several possible complexing agents.

\begin{tabular}{|c|c|c|c|c|c|c|c|c|c|}
\hline \multirow[t]{3}{*}{ Colouring agent } & \multirow[t]{3}{*}{ Reagent } & \multicolumn{4}{|c|}{ Acidic medium $\left(0.05 \mathrm{M} \mathrm{H}_{2} \mathrm{SO}_{4}\right)$} & \multicolumn{4}{|c|}{ Close-to-neutral ( $1 \times 10^{-2} \mathrm{M}$ HEPES $)$} \\
\hline & & \multicolumn{2}{|l|}{ Without NFX } & \multicolumn{2}{|c|}{ With NFX } & \multicolumn{2}{|l|}{ Without NFX } & \multicolumn{2}{|l|}{ With NFX } \\
\hline & & Colour & OP & Colour & OP & Colour & OP & Colour & $\mathrm{OP}$ \\
\hline $\mathrm{Fe}(\mathrm{III})$ & $\mathrm{FeCl}_{3} \cdot 6 \mathrm{H}_{2} \mathrm{O}$ & - & - & Orange & - & - & - & Orange & - \\
\hline $\mathrm{Al}(\mathrm{III})$ & $\mathrm{Al}\left(\mathrm{NO}_{3}\right)_{3} \cdot \mathrm{H}_{2} \mathrm{O}$ & - & - & - & - & - & - & - & - \\
\hline $\mathrm{Pb}(\mathrm{II})$ & $\mathrm{Pb}\left(\mathrm{NO}_{3}\right)_{2}$ & White & $\mathbf{p}$ & White & $\mathbf{p}$ & - & - & White & pp \\
\hline Aluminon & Triammonium salt & Dark orange & pp & Dark orange & pp & Dark orange & - & Dark Pink & - \\
\hline Mo(II) & $\left(\mathrm{NH}_{4}\right)_{6} \mathrm{Mo}_{7} \mathrm{O}_{24} .4 \mathrm{H}_{2} \mathrm{O}$ & - & - & Light green & pp & - & - & White & $\mathbf{p}$ \\
\hline $\mathrm{Mn}(\mathrm{II})$ & $\mathrm{MnCl}_{2} .4 \mathrm{H}_{2} \mathrm{O}$ & - & - & - & - & - & - & Light brown & - \\
\hline $\mathrm{Ni}(\mathrm{II})$ & $\mathrm{N}_{2} \mathrm{NiO}_{6} \cdot 6 \mathrm{H}_{2} \mathrm{O}$ & Light green & - & Light green & - & Light green & - & Light green & bp \\
\hline $\mathrm{Cu}(\mathrm{II})$ & $\mathrm{CuCl}_{2} \cdot 2 \mathrm{H}_{2} \mathrm{O}$ & - & - & - & - & Light blue & - & Green & - \\
\hline $\mathrm{Co}(\mathrm{II})$ & $\mathrm{Co}\left(\mathrm{NO}_{3}\right)_{2} .6 \mathrm{H}_{2} \mathrm{O}$ & Light pink & - & Light pink & - & Light pink & - & Light violet & - \\
\hline $\operatorname{Sn}(I V)$ & $\mathrm{SnCl}_{4}$ & - & - & - & - & - & - & - & - \\
\hline $\mathrm{V}(\mathrm{V})$ & $\mathrm{xXX}$ & Light green & - & - & - & Light green & - & - & - \\
\hline
\end{tabular}

OP: Observed Precipitate. 
This was a necessary procedure because Fe(III) displayed a small yellow colour that intensified for increasing concentrations and absorbed at the $1_{\max }$ of the complex.

The differential absorbance obtained was plotted in (Fig. S2) and two linear segments could be found. One segment had a positive slope, corresponding to an increase of the complex concentration. This was observed until no more free NFX was available. After that, the absorbance could no longer increase. It remained nearly constant, leading to the second linear segment (zero slope). The intercept point of these two segment corresponded to an iron concentration of $1.0 \times 10^{-4} \mathrm{M}$. Since NFX in the solution was $1.0 \times 10^{-4} \mathrm{M}$, the molar ratio of the Fe(III)/NFX complex was $1: 1$.

\subsubsection{Formation constant}

The formation constant $\left(K_{f}\right)$ of the complex was calculated by applying a suitable mathematical treatment (Ghosh and Sharma, $2005)$ to the previous data. For this purpose, $\log \left[\left(A_{\max }-A_{x}\right) /\right.$ $\left.\left(A_{x}-A_{0}\right)\right]$ was plotted against $\log [\mathrm{Fe}(\mathrm{III}), \mathrm{M}]$, where $A_{0}$ and $A_{\max }$ were minimum and maximum absorbancies, respectively, and $A_{x}$ the given absorbance for a specific $\mathrm{Fe}(\mathrm{III})$ concentration. The $x$ axis intercept of the corres ponding linear trend corresponded to the $\log K_{f}$ value. $K_{f}$ was therefore 14,420 , pointing out that the complex was formed in a high extent.

\subsubsection{Reading time}

The reading time of the coloured complex started after a steady absorbance was reached and ended when the colour started fading or changing. After monitoring the changes in the absorbance over time (Table S1), it was clear that the complex was formed almost instantaneously and remained stable within $90 \mathrm{~min}$. After that, the absorbance was monitored on the following day and decreased significantly, mostly for the higher concentrations. Thus, any analytical information relying on colour measurement was taken within 1-90 min.

\subsection{Ligand concentration}

An exceeding concentration of $\mathrm{Fe}(\mathrm{III})$ should guarantee and promote the rapid complexation of NFX molecules in a wide concentration range. To find out the necessary excess leading to analytical advantages, several calibrations were plotted for a range of NFX solutions $\left(1.8 \times 10^{-5}\right.$ to $\left.7.1 \times 10^{-4} \mathrm{M}\right)$ prepared with a constant concentration of $\mathrm{Fe}(\mathrm{III})$, lying between $4 \times 10^{-4}$ and $1 \times 10^{-2} \mathrm{M}$ (Fig. S3). The exact concentration of iron used corresponded to $17,1.9$ and 0.5 times that required to complex all NFX molecules in the most concentrated standard.

For the highest concentration of iron, the molar extinction coefficient was $2959.3 \mathrm{~L} / \mathrm{mol} \times \mathrm{cm}$ from $1.8 \times 10^{-5}$ to $7.1 \times 10^{-4} \mathrm{M}$ NFX solutions. The intermediate iron concentration gave lower e values $(1800 \mathrm{~L} / \mathrm{mol} \times \mathrm{cm})$ and narrower linear ranges $\left(7.1 \times 10^{-5}\right.$ and $\left.7.1 \times 10^{-4} \mathrm{M}\right)$. The lowest iron concentration displayed an even lower slope $(838.0 \mathrm{~L} / \mathrm{mol} \times \mathrm{cm})$ linked to narrower NFX concentration ranges.

The above results pointed out that a great excess of iron over NFX ensured higher slope, widened the linear range and decreased the concentration after which the system responded linearly. Thus, all further experiments were carried out with a great excess of iron.

\subsection{Aqueous-based selectivity}

Other divalent/trivalent metals regularly found in environmental waters may interfere in the formation of the coloured complex between Fe(III) and NFX (Gao et al., 1995; Wallis et al., 1996). Following the usual chemical requirements for waters
(Decreto-lei 243/2001, 2001), Fe(II), Mn(II), Cu(II), Zn(II), Cd(II), $\mathrm{Pb}(\mathrm{II}), \mathrm{Hg}(\mathrm{II})$ and $\mathrm{Ba}(\mathrm{II})$ were studied as possible interfering species. These were selected considering the metal species that may be found in environmental waters and that NFX may form complexes with divalent species. Some of the concentrations tested followed the limiting values of Portuguese environmental waters (Decreto-lei 243/2001, 2001).

The interference of each foreign ion was measured by means of the positive or negative errors induced in NFX readings (Table S2). The obtained values ranged from -9.6 to $\mathrm{p} 7.9 \%$. Only Mn(II) $\mathrm{Cd}(\mathrm{II})$ e $\mathrm{Pb}(\mathrm{II})$ were outside this range, but the corresponding concentrations are in general higher than those expected in environmental waters.

\subsection{Solid-state probe preparation}

The probe consisted on $\mathrm{Fe}(\mathrm{III})$ included in a plasticized PVC membrane. The exact composition was established after selecting the amount of ligand and the kind/amount of plasticizer ensuring the best analytical performance.

\subsubsection{Ligand concentration}

Different percentages of iron were included in the membrane ranging from 61 to $91 \%(\mathrm{w} / \mathrm{w})$. All these were tested in duplicate for a set of NFX standard solutions, between $1 \times 10^{-3}$ and $1 \times 10^{-5} \mathrm{M}$. A "zero" concentration standard was used as blank. The obtained results were indicated in Fig. 1.

It seemed obvious that a higher amount of iron would favour the formation of the coloured complex. However, the yellow colour of the blank probe turned out more intense for increasing amounts of ligand, which hindered the perception of the colour changes within different NFX concentrations (Fig. 1). The probe became also difficult to manipulate, showing an heterogeneous pattern in some cases. Although this is difficult to see in the presented pictures, it was clear in the laboratory that the highest and more consistent colour gradient was obtained when $72 \%$ of iron was included in the membrane. This condition was set in further experiments.

\subsubsection{Plasticizer}

The plasticizer favoured the ion-exchange between the membrane and the aqueous phase. It affected the permittivity and porosity of the membrane, for which the kind/amount of mediating solvent were carefully selected.

BES, oNPOE, DOP, DBP, BEP e PGE were tested as plasticizers. The iron salt was not soluble in oNPOE/PVC solutions, forming irregular clumps after THF evaporation. Conversely, the PGE allowed complete dissolution of the metal salt, giving an intense orange colour to the final membrane. The other membranes showed an intermediate behaviour (Fig. 2, top-left). After dropping NFX solutions of increasing concentrations on top of each probe, the colour gradient was evident for all plasticizers, except PGE (Fig. 2, top-rigth). BES was selected because it was the one showing the higher sensitivity, with a more intense colour gradient.

The amount of BES was selected after checking the behaviour of $3-23 \%$ plasticized-PVC membranes (Fig. 2, down). In general, only membranes with the higher amount of BES behaved differently: the final probe showed a more homogeneous pattern but the colour gradient became less perceptible. Thus, BES was set to $16 \%$, ensuring a homogenous membrane changing the colour more intensely with the concentration.

\subsection{Analytical features of the solid-state probe}

\subsubsection{Calibration parameters}

The optical-probe was prepared with about $0.500 \mathrm{~g}$ Fe(III), $0.050 \mathrm{~g}$ PVC and $0.100 \mathrm{~g}$ BES in $2 \mathrm{~mL}$ THF. The analytical response 


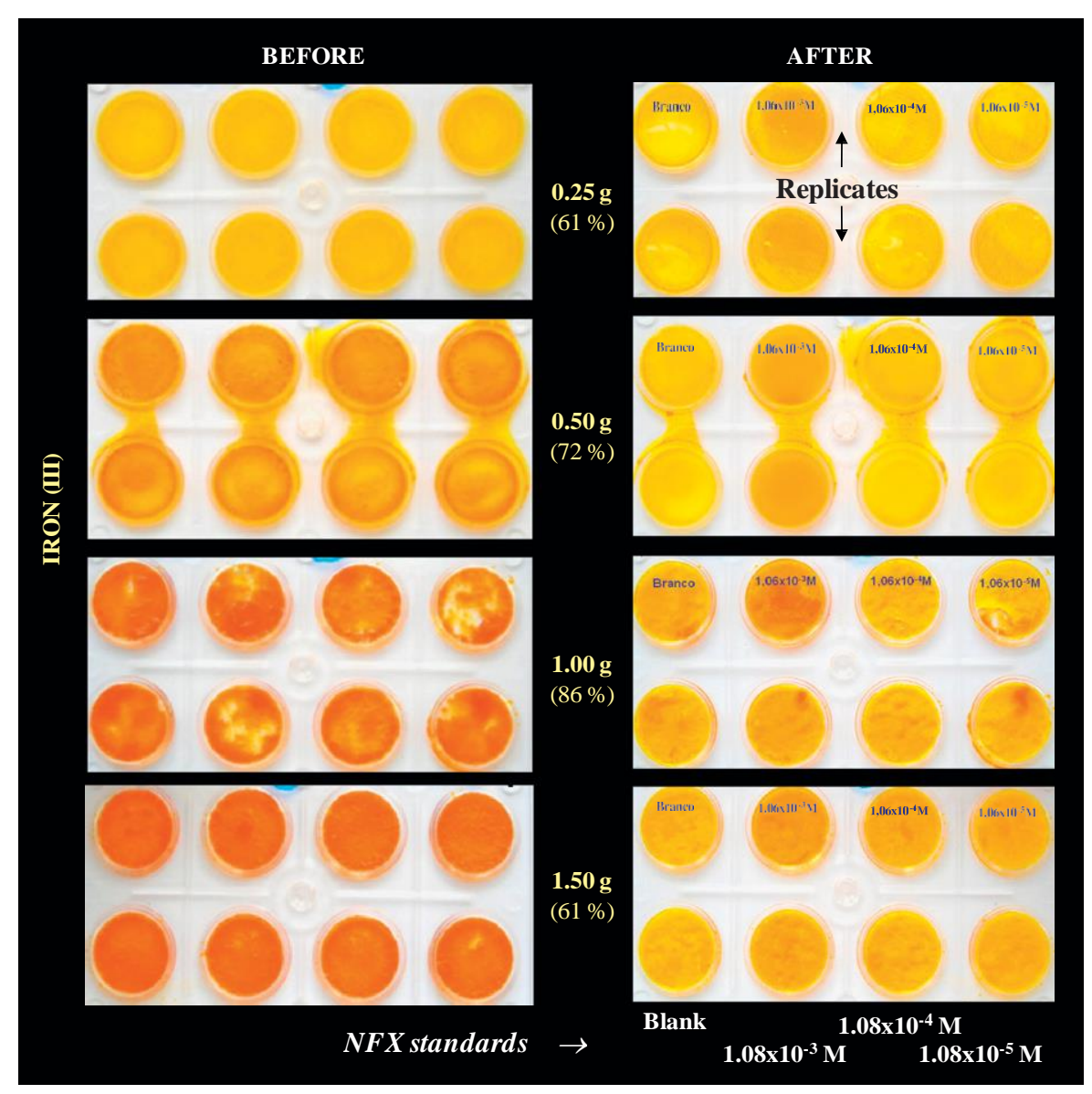

Fig. 1. Solid-state probes prepared with different amounts of iron.

of the solid-state probe was tested by casting over each well $200 \mathrm{~mL}$ of a specific NFX standard solution: $1.00 \times 10^{-2}, 4.00 \times 10^{-3}$; $2.00 \times 10^{-3} ; 1.00 \times 10^{-3} ; 5.00 \times 10^{-4}$ and $5.00 \times 10^{-5} \mathrm{M}$. The final colour (Fig. 3, top) was reached in less than $1 \mathrm{~min}$. The results showed a clear colour gradient for all concentrations; even $5.00 \times 10^{-5} \mathrm{M}$ was different from the blank test that was carried out by depositing only buffer.

For analytical purposes, the colour was measured by photographing the probes with a regular digital camera and opening the file on the Paint program. The colour coordinates were taken for each probe in several points of the picture using the HSL model. As expected, the results did not display a linear trend between concentration and any of the coordinates. Several mathematical approaches were then taken on these variables. A linear correlation was established when the logarithm of the concentration of NFX was changed against (Huep Lightness), as indicated in Fig. 3, top.

A more detailed colour gradient was also obtained by preparing a higher number of standards within the same concentration range indicated above. Extraction of the corresponding colours enabled the production of a "colour card" that may be used in field applications by direct colour comparison (Fig. S4). The pictures of the corresponding sensory platforms are also presented in Fig. S5.

\subsubsection{Selectivity against fluoroquinolones}

The response of the sensor probe against other members of the fluoroquinolone group was checked with enrofloxacin. The crossresponse to other antibiotics belonging to different chemical groups was also checked in parallel. This study was conducted by depositing on independent optimised probes solutions of NFX, tetracycline, sulfadiazine, chlorpromazine, enrofloxacin, trimethoprim and oxytetracycline, of equal concentrations. The results obtained are depicted in Fig. 3, bottom.

As expected, enrofloxacin showed the same orange colour as NFX, indicating that the reaction involved is typical of the fluoroquinolone group. The different colour intensities observed in these two members had no effect in terms of quantitative information. First these are not used in combination for veterinary therapy and second the fish farmer knows the drug that was applied to the fish.

Trimethoprim and sulfadiazine, used in association for human or veterinary therapy, were very close to the control (blank), indicating that they did not reacted with the $\mathrm{Fe}$ (III) or the extent of reaction was too small to be detected. Chlorpromazine showed a pink colour, very different from the other observed colours. The two tetracyclines (oxytetracycline and tetracycline) gave similar results, producing a compound of brown colour. In essence, the presence of non-fluoroquinolone drugs can be easily and quickly detected, because they originate very different colours in the probe. In addition, in case no information about the drug in the tank exists, the probe may always help producing qualitative data about the chemical drug in use.

\subsection{Solid-state probe array}

With the purpose of increasing the accuracy of the determination, an array of optical probes was developed. Ligands with the ability of forming coloured compounds with NFX (Section 3.1.1) were now immobilized in plasticized PVC. Aluminon, $\mathrm{Cu}(\mathrm{II})$ and $\mathrm{Mn}(\mathrm{II})$ were selected for this purpose. Only preliminary experiments 


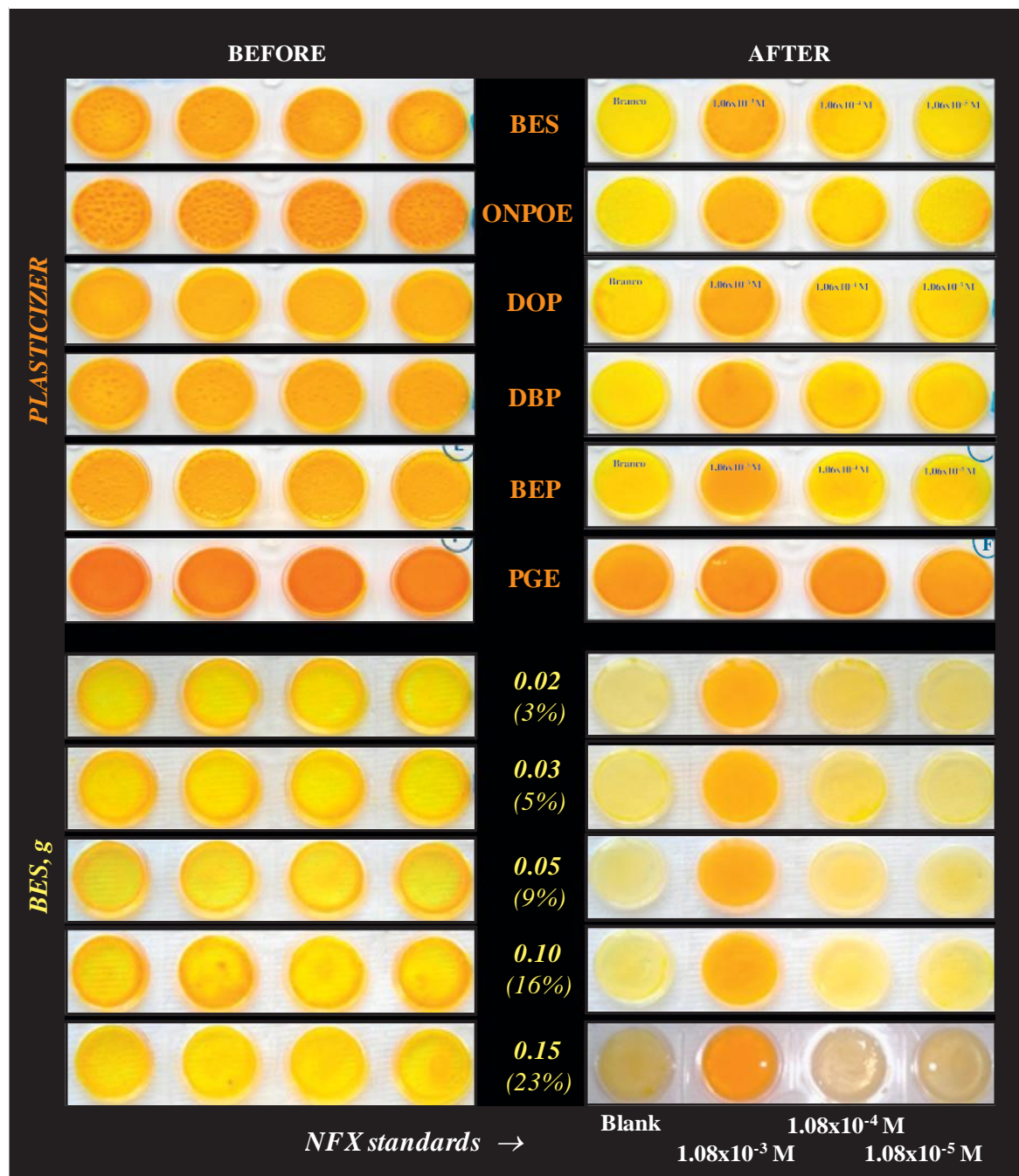

Fig. 2. Solid-state probes prepared with different kind of plasticizer and different amounts of BES.

\section{CALIBRATION for $\mathrm{NFX}(\mathrm{M})$}
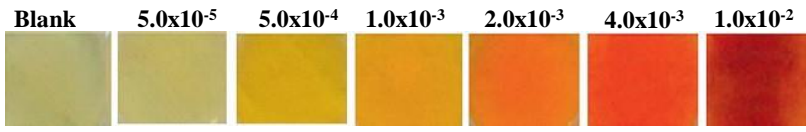

$($ Hue + Lightness $)=-\mathbf{2 8 . 7 5 9} \times \log [\mathrm{NFX}, \mathrm{M}]+\mathbf{3 4 . 3 8 4} \quad\left(\mathrm{R}^{2}=\mathbf{0 . 9 9}\right)$

\section{SELECTIVITY TRIAL $\left(1.0 \times 10^{-3} \mathrm{M}\right)$}

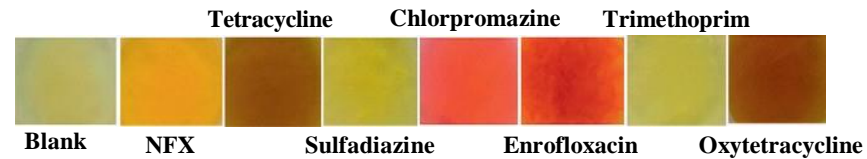

Fig. 3. Calibration of the optimised Fe(III) probe and its response against other antibiotic drugs.

were carried out, using the previously selected mass composition to prepare the membrane probes.

Calibration curves were carried out by depositing in each well a solution of NFX lying within the same concentration range as that indicated in Section 3.5.1. The obtained colour gradient, the corresponding digital images and the equation curves are indicated in Fig. 4. In general, Aluminon and $\mathrm{Cu}$ (II) probes behaved similarly to $\mathrm{Fe}(\mathrm{III})$, and only $\mathrm{Mn}$ (II) probe required a second degree function. These additional probes required further optimization steps, as the colour gradient is not very intense along the NFX concentration range studied.

\subsection{Application}

The array of optical probes was tested on environmental water samples. These had no drugs and had to be spiked with NFX. The calibration and the sample readings are indicated in Fig. 5. The obtained relative errors are also indicated in the same figure. In general, the results pointed out that only the iron probe provided accurate results, with relative errors (RE) below $10 \%$. The other probes served only to increase the selectivity of the determination, as different drugs would provide different colours. It was also apparent that specific optimization procedures would be required to improve the analytical performance of these additional probes.

In essence, the array may be use to fast screen fluoroquinolones/NFX or identify other drug in aquaculture fish-farming activities. The concentration range of the sample was perceptible to human eye, but it could be more accurately estimated after digital image acquisition. It is important to ensure that the reading time of about $1 \mathrm{~min}$ is correct when a new kind of sample is tested for the first time. In this case, the colour stability within time should be checked first. 


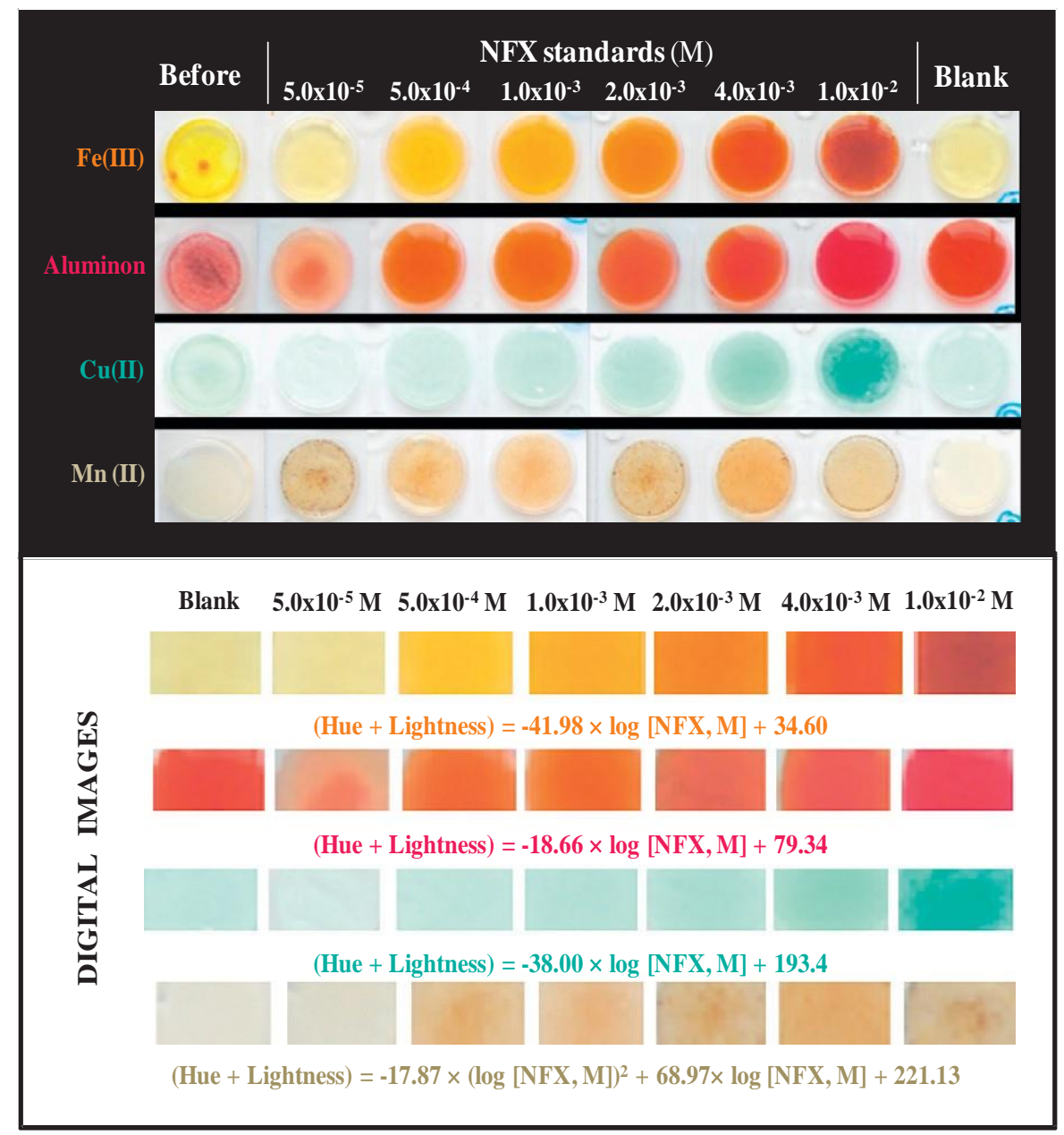

Fig. 4. Typical analytical response of the array of solid-state optical probes coming from the digital images.

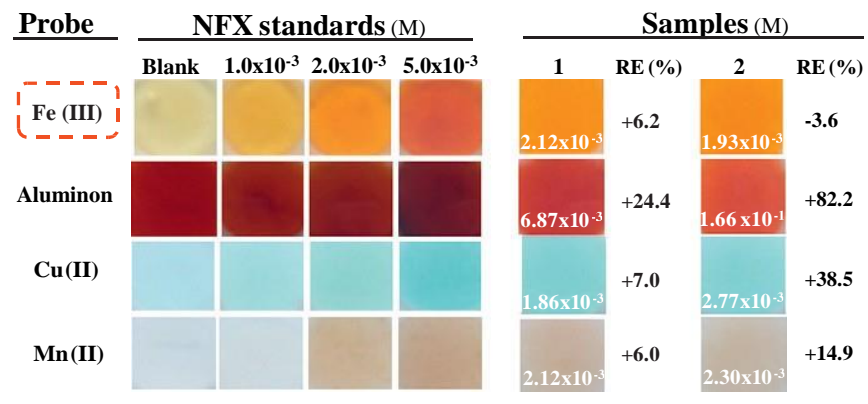

Fig. 5. Array calibration with three NFX standards and the analysis of two samples, along with the corresponding relative errors (RE) in \%.

\section{Conclusions}

A low cost disposable optical probe was developed for quick screening fluoroquinolones in aquaculture environment, being this concept applied to NFX determination. It consisted on immobilizing $\mathrm{Fe}(\mathrm{III})$ in a PVC/BES matrix. Surface colour changes were obtained quickly and easily detected by naked eye. The resulting colour intensity observed by a digital camera was directly proportional to log of NFX concentration allowing a more accurate quantification. The probe displayed a high selectivity for the target analyte and helped identifying other antibiotic drugs. A preliminary array was developed with additional NFX ligands originating coloured products. It showed great potential to enhance the accuracy and the selectivity in field applications, although additional optimization steps are required for practical use.

\section{Acknowledgements}

The authors acknowledge the financial support from FCT, Fundac-ro para a Ciennciae Tecnologia/FEDER, by means of project PTDC/AGR-AAM/68359/2006.

\section{Appendix A. Supplementary Information}

Supplementary data associated with this article can be found in the online version at http://dx.doi.org/10.1016/j.bios.2012.04.018.

\section{References}

Beausse, J., 2004. Trends in Analytical Chemistry 23, 53-761.

Cabello, F.C., 2004. Reviews in Medicinal 132, 1001-1006.

Chui-Shiang, C., Wei-Hsien, W., Chin-En, T., 2008. Journal of Food and Drug Analysis 16, 87-96.

Decreto-lei 243/2001, 5 de Setembro de 2001, Ministé rio do Ambiente e do Ordenamento do Territo rio, Dia rio da Repu`blica, Série A, 206, 5754.

Díaz-Cruz, M.S., Lopez de Alda, M.J., Barcelo’, D., 2003. Trends in Analytical Chemistry 22, 340-351.

Dufresne, G., Fouquet, A., Forsyth, D., Tittlemier, S.A., 2007. Journal AOAC International 90. 604-312.

Gao, F., Yang, P., Xie, H. J., J., 1995. INFX Biochemistry 60, 61-67. 
Ghosh, K.K., Sharma, P., 2005. Journal of Dispersion Science and Technology 26, 723-728.

Guerreiro, J.R.L., Sales, M.G.F., 2011. Microchimica Acta 175, 323-331.

Hoope, D.C., 2001. Emerging Infectious Diseases 7, 337-341.

Hueta, A.C., Charliera, C., Singh, G., Godefroy, S.B., Leivoc, J., Vehnia"inen, M., Nielen, M.W.F., Issopoulos, P.B., 1989. Analyst 114, 627-630.

Jeon, C.W., Khan, M.A., Lee, S.H., Karim, M.M., Lee, H.K., Suh, Y.S., Alam, S.M., Chung, H.Y., 2008. Journal in Fluorescence 18, 843-851.

Jeronimo, P.C.A., Araujo, A.N., Montenegro, M.C.B.S.M., 2007. Talanta 72, 13-27.

Karthikeyan, K.G., Meyer, M.T., 2006. Science of the Total Environment 361, 196-207.

Kassab, N.M., Singh, A.K., Kedor-Hackman, E.R.M., 2005. Brazilian Journal of Pharmaceutical Sciences 41, 507-513.

Kaur, K., Kumar, A., Malik, A.K., Singh, B., Rao, A.L.J., 2008. Critical Reviews in Analytical Chemistry 38, 2-18.

Khezri, B., Amini, M.K., Firooz, A.R., 2008. Analytical and Bioanalytical Chemistry 390, 1943-1950.
McCourt, J., Bordin, G., Rodriguez, A.R., 2003. Journal of Chromatography A 990, 259-269.

Narayanaswamy, S.M.N., 2006. Analytical and Bioanalytical Chemistry 386, 1235-1244.

Park, S.K., Kim, M., Sho, Y.S., Chung, S.Y., Hu, S., Lee, J.O., Hong, M.K., Kim, M.C., Kang, J.S., Jhee, O.H., 2007. Food Science and Biotechnology 16, 868-872.

Pico', Y., Andreu, V., 2007. Analytical and Bioanalytical Chemistry 387, 1287-1299. Schneider, M.J., Vazquez-Moreno, L., Bermudez-Almada, M.D., Guardado, R.B., Ortega-Nieblas, M., 2005. Journal AOAC International 88, 1160-1166.

Wallis, S.C., Charles, B.G., Gahan, L.R., Filippich, L.J., Bredhauer, M.G., Duckworth, P.A., 1996. Journal of Pharmaceutical Sciences 85, 803-809.

Wolfbeis, O.S., 2008. Analytical Chemistry 80, 4269-4283.

Zhang, Y.Z., Zhang, Z.Y., Zhou, Y.C., Liu, L., Zhu, Y., 2007. Journal Zhejiang University Science B 8, 302-306. 